Proceedings of the 2011 Winter Simulation Conference

S. Jain, R.R. Creasey, J. Himmelspach, K.P. White, and M. Fu, eds.

\title{
USING DISCRETE-EVENT SIMULATION FOR EVALUATING NON-LINEAR SUPPLY CHAIN PHENOMENA
}

\author{
Edgar E Blanco \\ $\mathrm{Xu}$ (Cissy) Yang \\ Erica Gralla \\ MIT Center for Transportation \& Logistics \\ 77 Massachusetts Ave, E40 - 276 \\ Cambridge, MA 02139, USA
}

\author{
Gary Godding \\ Emily Rodriguez
}

Intel Corporation

5000 W Chandler Blvd

Phoenix, AZ 85224, USA

\begin{abstract}
We present a simulation model constructed in collaboration with Intel Corporation to measure and gauge the interaction of non-linear supply chain phenomena (such as waste, uncertainty, congestion, bullwhip, and vulnerability). A representative model that mimics part of Intel's supply chain from fabrication to delivery is modeled using discrete-event simulation in ARENA. A "phenomena evaluation" framework is proposed to link model inputs and supply chain phenomena in order to evaluate supply chain configurations. Using a sample supply chain decision (safety stock level determination) we follow the "phenomena evaluation" framework to illustrate a final recommendation. Results show that our supply chain phenomena evaluation approach helps better illustrate some trade-offs than an evaluation approach based only on the traditional metrics (cost, service, assets etc.).
\end{abstract}

\section{INTRODUCTION}

Over the last 20 years, supply chain management has been recognized as an important source of competitive advantage. A significant body of knowledge has been developed to describe multiple dimensions of detrimental performance of supply chain systems.

Several authors describe sub-optimal performance of supply chain systems and opportunities for improvement by viewing the supply chain in a holistic manner (Bechtel and Jayaram 1997; Cooper et al. 1997; Lee and Billington 1992). Simchi-Levi et al. (2008), for example, describes the inherent supply chain trade-offs between cost and customer service and how the impact of these trade-offs can be eliminated or, at least, reduced through the use of advanced information technology and appropriate supply chain design. Sheffi (2005) discusses the trade-offs between inventory level and disruption vulnerability, as well as the impact of the postponement strategy in developing supply chain resilience. Christopher (2005) illustrates the inherent trade-offs of global logistics. In summary, firms are constantly looking for new practices, or combinations of old ones, that help eliminate or reduce existing trade-offs to create sustainable competitive advantage (Hewitt 1994; Porter 1996).

One of the challenges of developing new practices is the multi-dimensional nature of trade-offs required to evaluate supply chain design decisions. Blanco et. al. (2009) and Barros et. al (2010), as part of the "Tailored Supply Chains" project supported by Intel Corporation, identified "Seven Non-Linear Supply Chain Phenomena" and argued that this framework allows for better understanding - and ultimately better design - of supply chains. These phenomena are: the bullwhip effect, vulnerability, uncertainty, congestion, waste, diseconomies of scale and self-interest. 
Table 1: The seven non-linear supply chain phenomena

\begin{tabular}{|l|l|}
\hline Phenomena & Description \\
\hline Waste & Use of resources without creating value \\
\hline Vulnerability & Inability to recover from disruptive events \\
\hline Uncertainty & $\begin{array}{l}\text { Inability to predict the future due to incomplete knowledge or chang- } \\
\text { ing environment }\end{array}$ \\
\hline Congestion & Excessive accumulation of products, processes, or information \\
\hline Bullwhip & Upstream amplification of demand signals \\
\hline Diseconomies of Scale & Increase of unit cost as output increases \\
\hline Self-interest & Reduction of system wide profits, due to individual profit focus \\
\hline
\end{tabular}

The goal of our research is to develop analytical models that enable us to measure and gauge the interaction of the seven supply chain phenomena. This research will also increase our understanding of key supply chain metrics and their relationships with overall supply chain performance.

\section{THE MULTI-TIER SUPPLY CHAIN DYNAMICS SIMULATOR}

\subsection{Model Overview}

A multi-tier supply chain simulation model (MTSCSM) was developed, inspired by the dynamics of Intel "low cost" products. The goal of this model was to study how supply chain decisions could be evaluated from the seven-phenomena perspective.

In our study, phenomena are ways to classify the observable effects of the structure of the supply chain and the decisions made to operate it. For example, the congestion phenomenon may be observed in several ways in the supply chain: amount of queuing time in a factory, excess inventory levels in various points in the supply chain, and so on.

The model was developed in Arena (Version 12.00.00). Microsoft Excel is used to read and write data. When running multiple experiments, Excel Macros are used to help generate various experiments, set up Arena readable format inputs, and store all outputs.

In the MTSCSM model, some phenomena are configured by the input data and some phenomena are outputs that we can measure. Others must be measured using scenarios: for example, assigning a disruption to the resources with deterministic occurrence and duration to study vulnerability.

\subsection{Functional Components}

There are four functional components in the MTSCSM model: order generation, forecast, production, and delivery shown as four green blocks in Figure 1.

In the order generation component, original equipment manufacturer (OEM) orders are generated at the beginning of the simulation. All generated orders have a product type, order quantity, arrival time, change time, and due time. The orders are held until the time they should arrive in the system. In other words, the generated orders will not be "seen" by the model until they enter the system at their arrival time.

In each week, a stochastic forecast of OEM orders is generated (forecast component of the model). The forecast is generated around a forecast mean (which is the maximum between total orders generated and total "units ordered" that are visible to Intel), using a bias and standard deviation specified in the input parameters. This approach captures the uncertainty nature of forecasts experienced by Intel during the planning process. 


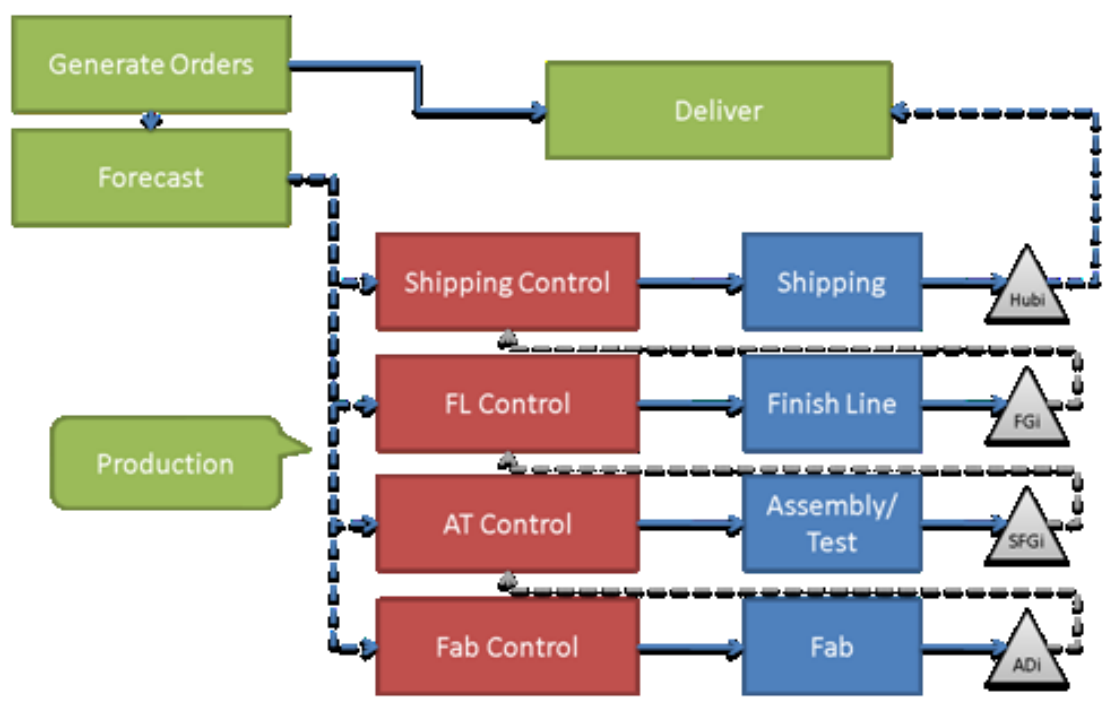

Figure 1: Four functional components in the simulation model

All production related activities occur in the production component where we mainly consider four processes - fabrication (Fab), assembly/test (AT), finish line (FL), and shipping. In Figure 2, blue blocks are production processes, and green triangles are the inventories held after completing each production process. In each production process, we model both the control/planning and execution phases. As in Figure 1 , red blocks represent the control/planning phase, and blue blocks are the execution phase in the model.

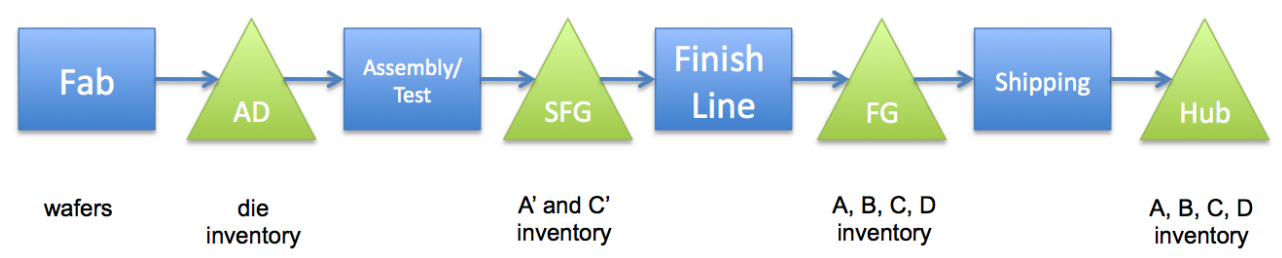

Figure 2: Production processes of fabrication, assembly/test, finish line, and shipping

As shown in Figure 2, the first stage of the production line is to fabricate silicon wafers and saw them into individual devices called die. The die then goes through the process of assembly/test, in which two product families A' and C' are produced. The two product families are referred to as semi-finished goods (SFGs) in the simulation model. SFGs then go through the finish line to be produced into finished goods (FGs). There are four types of FGs in the simulation model - products A, B, C, and D. At the end, FGs are transferred to the shipping process where the excess FGs are stored as hub inventory (Hub).

As orders become due (as assigned in the order generation component of the model), OEM orders are fulfilled from the Hub. In the delivery component of the model, filled orders are removed from Hub inventory, and orders that cannot be filled are held until additional Hub inventory is available. On-time and late orders are recorded. Perfect order percentage (which is the ratio of on-time orders to total orders) associated with each product type is calculated and written into model outputs file in Excel.

\subsection{Inputs and Outputs}

As in all discrete event simulation models, there are a large number of configuration elements that determine system performance. We focused on a set of 81 model inputs that represent the key supply chain decision parameters: Products and product families ( 2 parameters), forecast management (12 parameters), 
demand configuration (28 parameters), inventory control (21 parameters) and manufacturing execution (18 parameters).

The simulation model is configured to output a wide range of data after terminating each run. Model outputs are stored in an Excel output file. Some of the most useful outputs and their statistics are listed in Table 2.

Table 2: Selected model outputs.

\begin{tabular}{|l|l|l|}
\hline Order Statistics & & Statistics \\
\hline & Perfect order percentage & Avg/Max/Min \\
\hline & Hours late (late orders) & Avg/Max/Min \\
\hline Production Statistics & & \\
\hline & ADi, SFGi, FGi, Hub inventory & Avg/Max/Min/std \\
\hline & Total cycle time & Avg/Max/Min/std \\
\hline & Processing cycle time & $\mathrm{Avg} / \mathrm{Max} / \mathrm{Min} / \mathrm{std}$ \\
\hline & Queuing time & $\mathrm{Avg} / \mathrm{Max} / \mathrm{Min} / \mathrm{std}$ \\
\hline & Number in queue & $\mathrm{Avg} / \mathrm{Max} / \mathrm{Min} / \mathrm{std}$ \\
\hline & Quantity "Sold" & $\mathrm{Avg}$ \\
\hline & Quantity produced to FGi, Hub & $\mathrm{Avg}$ \\
\hline
\end{tabular}

\subsection{Baseline Configuration}

We configured a baseline model based on the data provided by Intel and our assumptions on some model inputs. All experimental runs are generated by modifying the input parameters in the baseline configuration. The setting of the baseline experiment is shown in Table 3. All numbers have been changed to protect Intel confidential information.

\section{SUPPLY CHAIN PHENOMENA EVALUATION FRAMEWORK}

The supply chain phenomena evaluation framework is constructed to abstract various types of supply chain performance into the undesirable phenomena and to evaluate supply chain performance from a systematic perspective. Due to the inherent difficulty in capturing diseconomies of scale and self-interest phenomena from the modeling perspective, we only formulate the simulation model so that five supply chain phenomena (waste, uncertainty, congestion, bullwhip, and vulnerability) can be captured and analyzed.

Traditional metrics (cost, service, assets etc.) have been used to evaluate supply chain decisions and measure performance for many years. For example, selecting the transportation mode may require a costbenefit analysis, and it may also require the consideration of sustaining satisfactory customer service level. However, due to the complexity of supply chains, supply chain decisions made merely based on traditional metric considerations may not capture some undesirable supply chain phenomena. Therefore, we propose a "supply chain phenomena evaluation framework" to link a supply chain decision/scenario to the presence and intensity of the undesirable/deadly phenomena in the supply chain. Figure 3 shows the proposed supply chain phenomena evaluation framework. 
Table 3: Baseline model input setting.

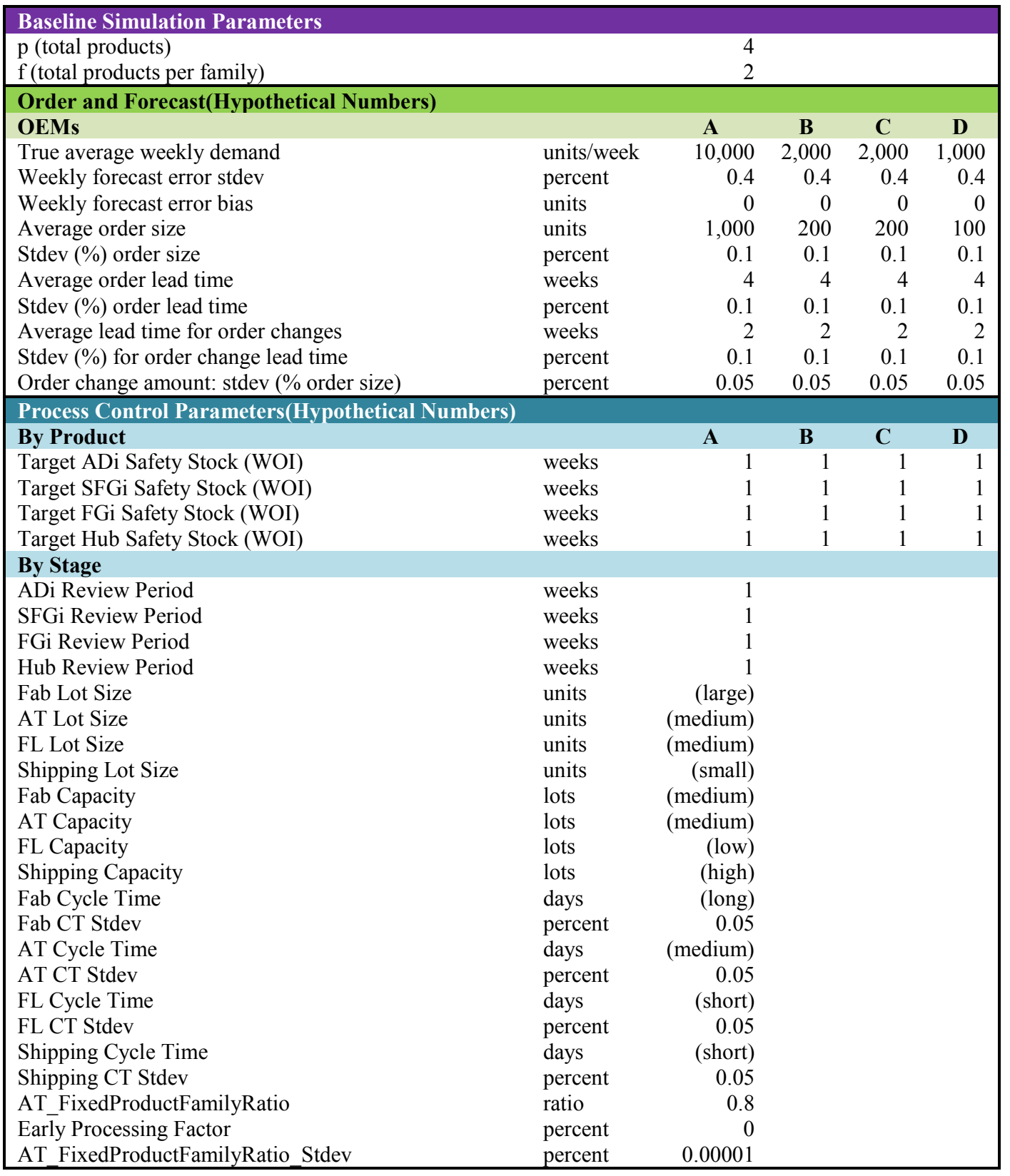




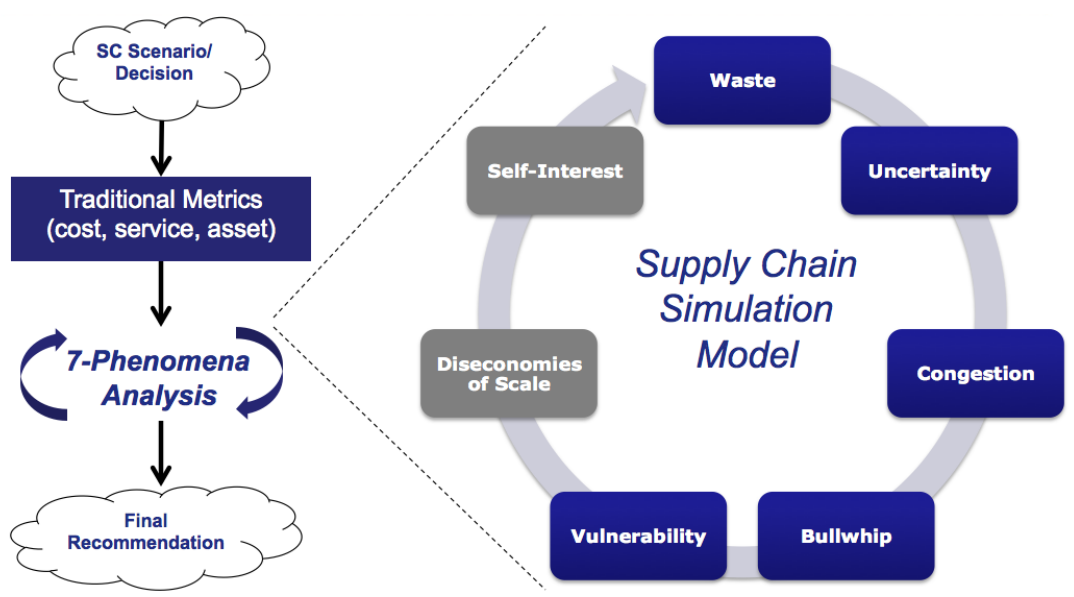

Figure 3: Supply chain phenomena evaluation framework

When there is a supply chain scenario or decision to be evaluated, the stakeholders start by looking at the traditional metrics and make a decision based on these metrics such as cost, service and so forth. The supply chain phenomena evaluation framework serves as an additional evaluation layer to guide through higher level interactions in the supply chain decision-making process. The MTSCSM simulation model is designed to link model inputs and outputs to the phenomena of waste, uncertainty, congestion, bullwhip and vulnerability in the supply chains. Once the phenomena evaluation process is finished, the process allows for a final recommendation based on both traditional metrics and phenomena evaluation. We provide a sample supply chain phenomena evaluation report in Section 4.

\section{PHENOMENA EVALUATION OF A SAMPLE DECISION}

In this section, we will demonstrate how to make a supply chain decision by following the "evaluation framework" (as shown in Figure 3) to quantitatively evaluate the presence and intensity of five supply chain phenomena.

\subsection{A Sample Decision}

In every supply chain, it is important to set up the right safety stock level because of its associated investment (money, time etc.). Most of the time, making such a decision can be difficult and timeconsuming. Moreover, there may be many unforeseen consequences (for example, waste) if we only consider the cost of a candidate decision. Hence, we use the safety stock decision as the illustration of our research findings hereafter, and follow the proposed supply chain phenomena evaluation process to reach a recommendation.

The simulation model has features that enable the observation of supply chain phenomena from various perspectives: some phenomena are captured by model inputs and outputs, while others must be measured using scenarios or multiple experiments. A supply chain decision, which could involve one or more model input parameters, needs to be configured at the beginning of the evaluation process (i.e. baseline setting). A number of experiments representing alternative decisions can be generated by varying the inputs from the baseline setting. After running all generated experiments, we can compare these decision alternatives and their supply chain performance, and understand the trade-offs among different decisions from the supply chain phenomena perspective.

\subsection{Phenomena Analysis}

We will now follow the sequence of the framework evaluation in Figure 3 to study the relationship between a safety stock decision and the supply chain phenomena. 


\subsubsection{Waste}

Initially, 26 experiments were generated from the baseline model with changes in safety stock levels. The safety stock level for each product at each stage in the supply chain was changed from 0 to 5 weeks of inventory, increasing by 0.2 in each experiment. Table 4 shows the key parameters changed in these 26 experiments.

Table 4: Key parameters changed in the 26 experiments.

\begin{tabular}{|l|c|c|c|c|}
\hline Key Parameters Changed & Experiment & Baseline Value (wk) & Change (wk) & New Value (wk) \\
\hline ADi Safety Stock_A, B, C, D & & & & \\
SFGi Safety Stock_A, B, C, D & $1-26$ & 1 & 0.2 & $0-5$ \\
$\begin{array}{l}\text { FGi Safety Stock_A, B, C, D } \\
\text { Hub Safety Stock_A, B, C, D }\end{array}$ & & & & \\
\hline
\end{tabular}

We first look at the perfect order percentage of all 26 experiments in order to capture the phenomenon of waste in the supply chain. As shown in Figure 4, the service levels (in terms of perfect order percentage) increase as the safety stocks increase. The first week of safety stock is able to achieve an acceptable supply chain performance (which is around 95\%). But the service levels improvements increase slowly until the safety stocks reaches a particular level which is 1.4 weeks of inventory.

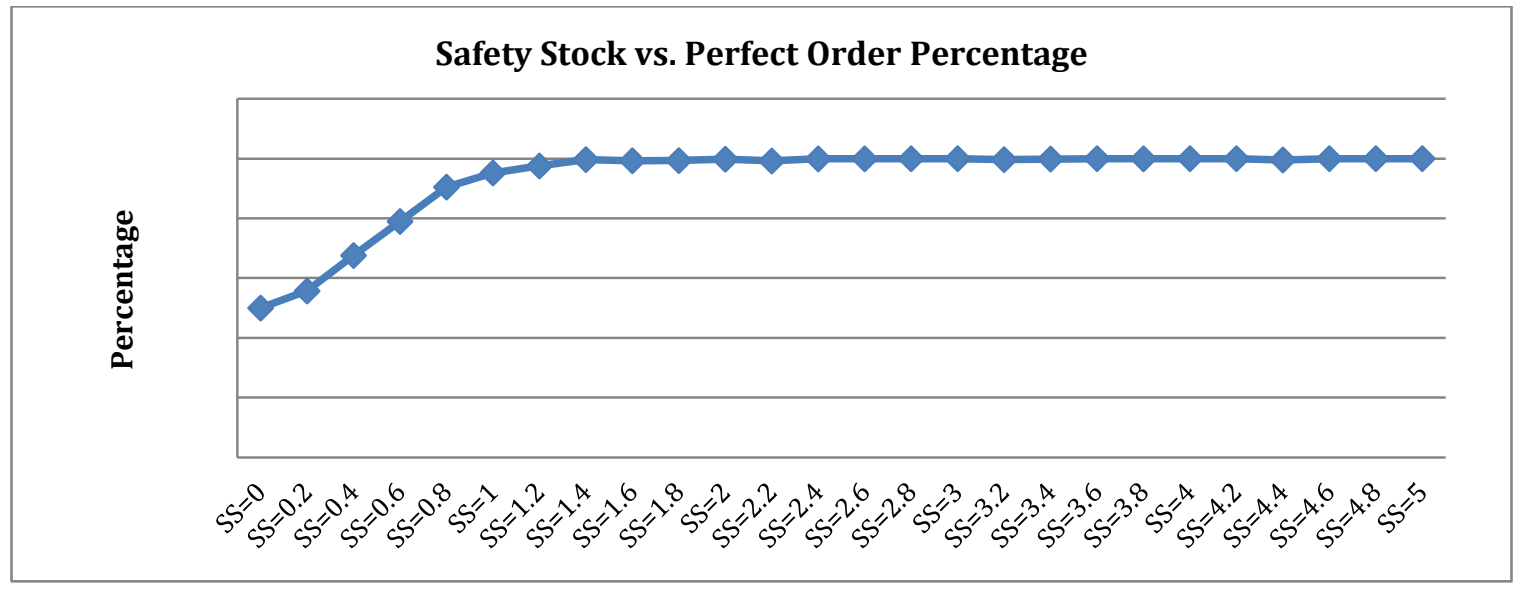

Figure 4: Safety stock levels and perfect order percentage

Figure 4 clearly shows that adding more safety stock does not necessarily yield a higher perfect order percentage. For example, keeping 1.4 weeks of the safety stock can reach $99.68 \%$ perfect orders, while keeping 2 weeks of safety stock yields $99.81 \%$ perfect orders. This illustrates that waste may be present in the supply chain due to marginal improvements in service levels. In other words, by linking alternative safety stock decisions to the outputs of perfect order percentage, potential inventory waste can be observed.

\subsubsection{Uncertainty}

In practice, one and two weeks of safety stock are both reasonable decision candidates. In order to evaluate viable safety stock alternatives from an uncertainty perspective, we choose one and two weeks of safety stock in the remaining phenomena evaluation process. (One week of safety stock achieves, on average, $95 \%$ perfect order percentage, and two weeks of safety stock achieves $99.81 \%$ perfect order percentage.) We generate 13 experiments for both one and two weeks of safety stock by varying weekly de- 
mand (Table 5). Since demand is the only parameter being changed in each of these experiments, the system utilization varies from $40 \%$ to $90 \%$. Our goal is to understand how consistently the system performs regarding both perfect orders and lateness.

Table 5: Key parameters changed in the 13 experiments.

\begin{tabular}{|l|c|c|c|}
\hline Key Parameters Changed & Experiment & Baseline Value (unit) & Change (unit) \\
\hline Average weekly demand_A & $1-13$ & High & 1000 \\
\hline Average weekly demand_B & $1-13$ & Medium & 200 \\
\hline Average weekly demand_C & $1-13$ & Medium & 200 \\
\hline Average weekly demand_D & $1-13$ & Low & 100 \\
\hline
\end{tabular}

In Figure 5, when using one week of safety stock, the system can achieve relatively good performance regarding perfect orders but with the risk of falling down to low service levels. The perfect order percentage ranges from $87 \%$ to $93 \%$; this quantifies the effect of uncertainty in the supply chain. If the safety stock is increased to two weeks, the perfect order percentage is centered on $95 \%$ which clearly demonstrates a sustained robustness of service levels. Thus, with two weeks of safety stock the system becomes less uncertain with "safer" settings (more safety stocks across all echelons in the model). Similarly, Figure 6 shows that the range of lateness is relatively high with one week of safety stock compared to two weeks of safety stock. From the uncertainty perspective, we learn that even though the system achieves $90 \%$ perfect orders with one week of safety stock, it cannot sustain such performance when demand varies; thus risk is identified. With two weeks of safety stock, the system consistently shows superior performance regarding both perfect orders and lateness.

In the following steps, we study more trade-offs between these two alternatives (one week and two weeks of safety stock) from different perspectives as described in the "phenomena evaluation framework".

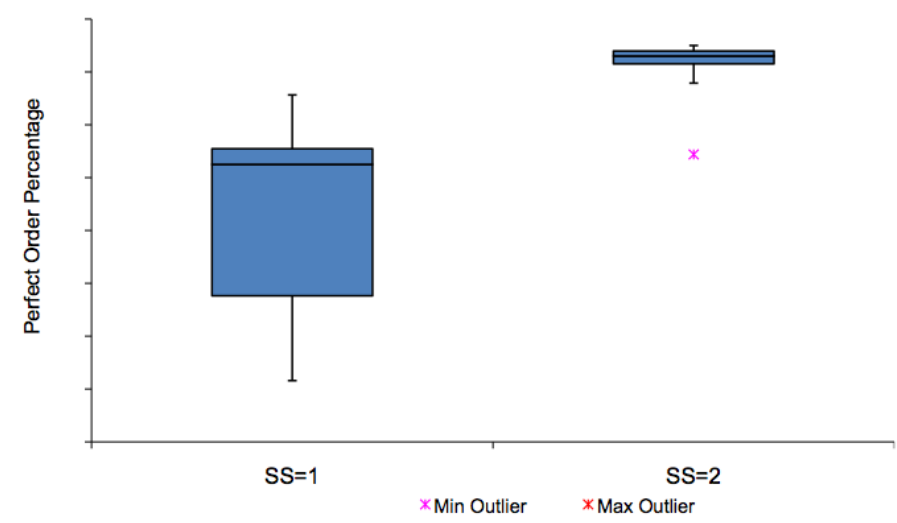

Figure 5: Safety stock levels (one and two weeks) and perfect order percentage 


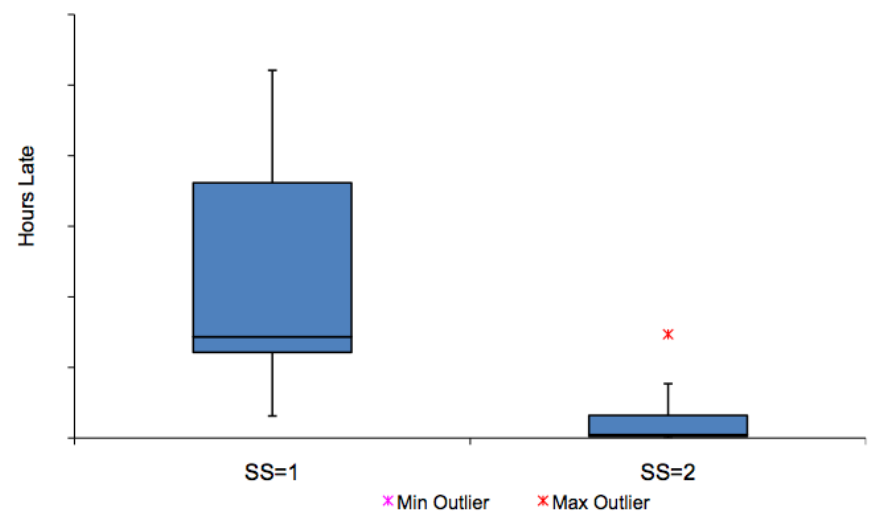

Figure 6: Safety stock levels (one and two weeks) and lateness

\subsubsection{Congestion}

A cycle time ratio is defined as the ratio of processing time over total cycle time at each stage (total cycle time is the sum of processing and queuing time). The ratio can be any value between 0 and 1 . On this definition, if the queuing time is 0 , the cycle time ratio is 1 , which shows no congestion in the system. If the queuing time is very large, the cycle time ratio goes to zero, which shows significant congestion. As a result, the larger the cycle time ratio, the better the system performs.

In Figure 7, two weeks of safety stock shows more congestion than one week of safety stock. This is because there is more excess inventory waiting /queuing in the system. The most congestion occurs at the finish line, since the cycle time at this stage is set to be short (as shown in Table 3).

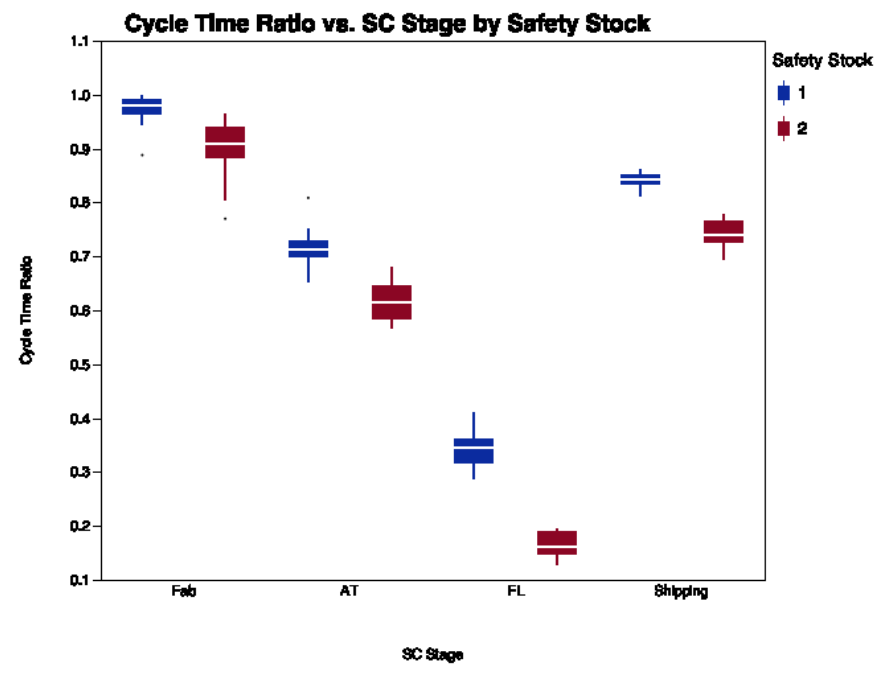

Figure 7: Safety stock levels (one and two weeks) and cycle time ratio at four supply chain stages

\subsubsection{Bullwhip}

In order to capture the bullwhip effect in the MTSCSM model, we observe system performance in terms of weeks of stock (WOS) at different supply chain stages (Figure 8). It shows that the downstream fluctuation (due to demand changes) is amplified towards upstream of the supply chain (except in the fab, because our model assumes unlimited material supply). 


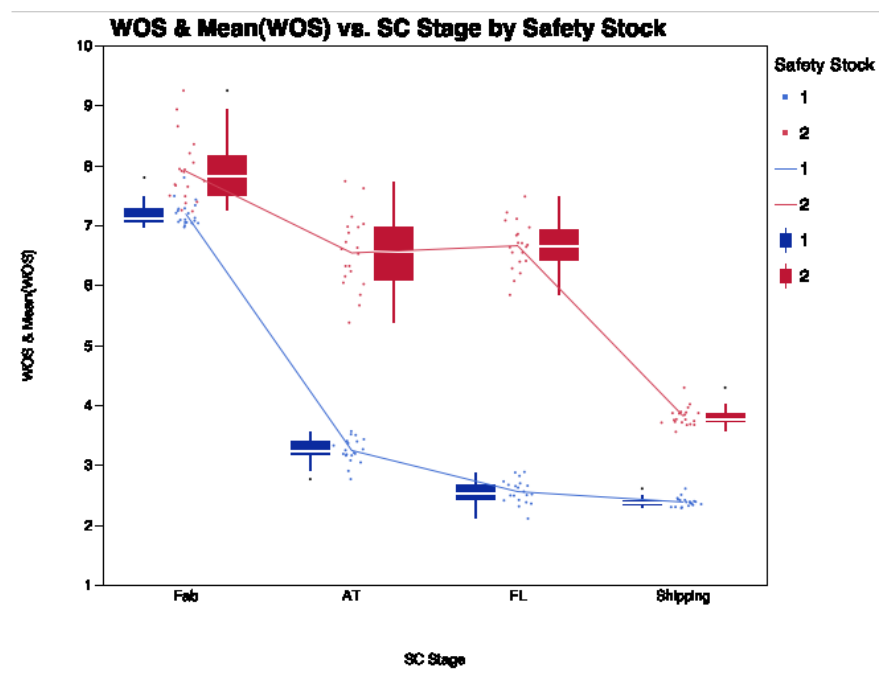

Figure 8: Safety stock levels (one and two weeks) and weeks of stock at four supply chain stages

\subsubsection{Vulnerability}

To study the vulnerability phenomenon, we design a "failure" with deterministic occurrence and duration in the simulation model. The failure occurs three weeks after the warm-up period (60 weeks) and lasts for eight weeks. The failure can be assigned to different production processes, such as fab, finish line and so on. Unlike the study of other phenomena using a set of experiments, we only use two experiments with one and two weeks of safety stock. We run the two experiments with no failure, failure at fab, and failure at finish line; thus, there are 6 experiments to study vulnerability. We mainly observe the accumulated numbers out of the system in each experiment to identify the system reaction and recovery to the disruption. Table 6 summaries some statistics of both Fab and FL failures with one week of safety stock. Better illustrations of accumulated numbers out of the system are shown in Figures 9 and 10.

Table 6: Statistics of Fab and FL failures for one week of safety stock.

\begin{tabular}{|c|c|c|c|c|c|c|}
\hline $\begin{array}{c}\text { Safety Stock= } \\
\text { 1 week }\end{array}$ & $\begin{array}{c}\text { Disruption } \\
\text { Start (wk) }\end{array}$ & $\begin{array}{c}\text { First } \\
\text { Drop } \\
\text { (wk) }\end{array}$ & $\begin{array}{c}\text { Recovery Be- } \\
\text { gin (wk) }\end{array}$ & $\begin{array}{c}\text { Second } \\
\text { Drop (wk) }\end{array}$ & $\begin{array}{c}\text { Second Recov- } \\
\text { ery (wk) }\end{array}$ & $\begin{array}{c}\text { Recovery } \\
\text { Finish (wk) }\end{array}$ \\
\hline Fab Disruption & 63 & 75 & 79 & 80 & 81 & 90 \\
\hline FL Disruption & 63 & 67 & 70 & 72 & 73 & 82 \\
\hline
\end{tabular}

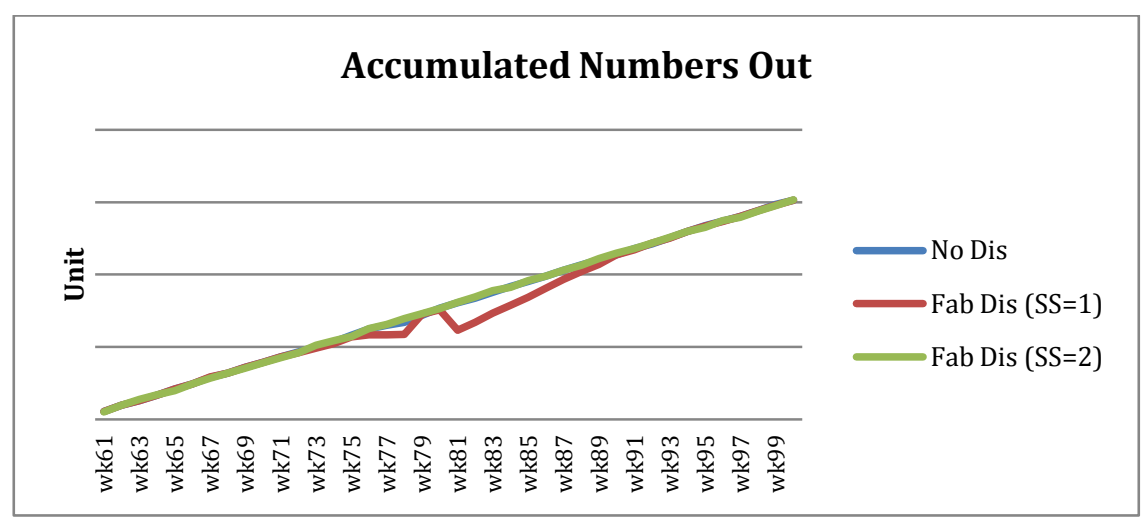

Figure 9: Accumulated number out of the system with Fab disruption 


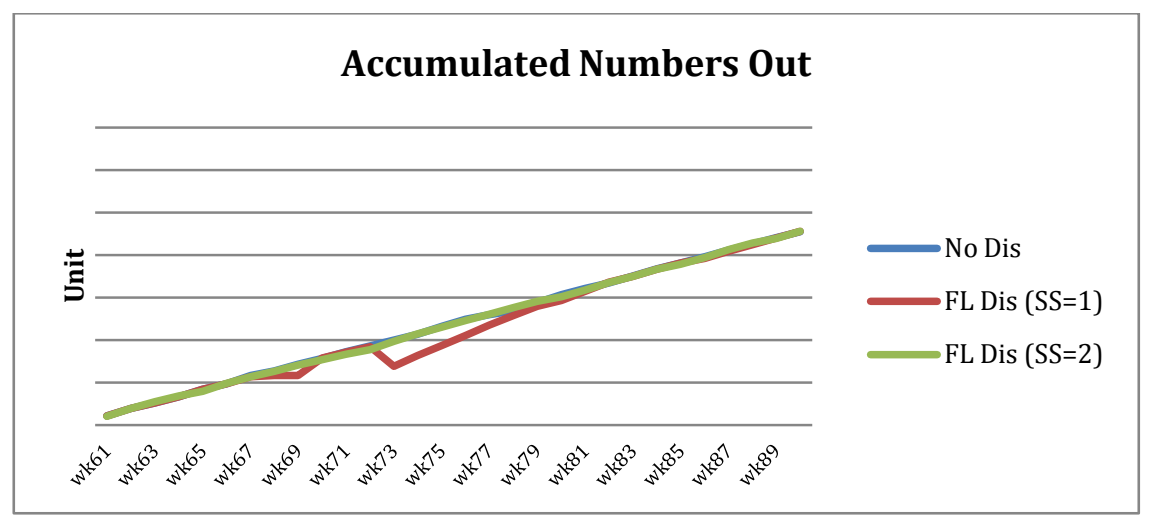

Figure 10: Accumulated number out of the system with FL disruption

In Figures 9 and 10, the most noticeable observation is that with two weeks of safety stock the system reacts well to the disruption (even though the disruption lasts for eight weeks). We also observe the reaction (first drop) to disruption occurs weeks after the disruption, and the recovery takes a long time to become steady. The "non-steady" recovery period is one week for the Fab disruption and two weeks for the FL disruption. When the failure occurs at the FL, the first drop occurs faster than with a failure at the Fab, because the FL is closer to downstream supply chain activities. Therefore, the numbers out of the system hurt more than the failure occurring at the upstream of supply chains.

In order to quantitatively evaluate the inventory loss associated with each failure, inventory "lost" is defined and measured in terms of weeks of inventory (the underneath area in both figures). There are 31 weeks of inventory lost for Fab Disruption and 20 weeks of inventory lost for FL Disruption. And for both cases, one week of safety stock loses more than using two weeks of safety stock.

\section{CONCLUSION}

We choose a sample decision and follow the supply chain phenomena evaluation framework to understand the trade-offs among decision alternatives. After evaluating many candidates of safety stock levels from the waste perspective, we narrow down the candidates to one and two weeks of safety stock, then analyze these candidates from other supply chain phenomena perspectives (uncertainty, congestion, bullwhip, and vulnerability). As shown in Table 7, both one week and two weeks of safety stock have advantages and disadvantages from different supply chain phenomena perspectives.

Table 7: Summary of supply chain phenomena evaluation and recommendation.

\begin{tabular}{|c|c|c|}
\hline Phenomena & $\mathrm{SS}=1$ week & $\mathrm{SS}=2$ weeks \\
\hline Waste & $\begin{array}{l}\sqrt{ } \text { Achieves target with minimal inventory } \\
\text { investment }\end{array}$ & $\begin{array}{l}\times \text { Superior service level with unnecessary inven- } \\
\text { tory investment }\end{array}$ \\
\hline Uncertainty & $\begin{array}{l}\times \text { Risk of lower performance; out-of-range } \\
\text { order lateness }\end{array}$ & $\sqrt{ }$ Consistently superior service level \\
\hline Congestion & $\sqrt{ }$ Normal behavior & $\begin{array}{l}\times \text { Increased waiting time across all supply chain } \\
\text { stages }\end{array}$ \\
\hline Bullwhip & $\sqrt{ }$ Acceptable inventory propagation & $\times$ Significant upstream inventory variability \\
\hline Vulnerability & $\times$ High risk to disruption & $\sqrt{ }$ Resilient \\
\hline
\end{tabular}

In conclusion, supply chain phenomena analysis is a systematic approach to complement the traditional metric evaluation approach. With the help of using discrete-event simulation models, the supply chain phenomena evaluation framework could serve as a strategic-level decision support tool to illustrate 
the trade-offs among alternative decisions from the perspectives of waste, uncertainty, congestion, bullwhip, and vulnerability. A final recommendation can be given based on traditional evaluation approach as well as phenomena evaluation approach.

\section{ACKNOWLEDGMENTS}

The authors would like to acknowledge the contributions of Stephanie Jernigan (MIT Center for Transportation \& Logistics), Mani Janakiram and Tosanwunmi Maku (Intel Corporation). This project was funded by the Intel Corporation Grant "Tailored Supply Chains" to the MIT Center for Transportation \& Logistics.

\section{REFERENCES}

Banks, J., J. S. Carson, B. L. Nelson, and D. M. Nicol. 2000. Discrete-Event System Simulation. 3rd ed. Upper Saddle River, New Jersey: Prentice-Hall, Inc.

Barros, A., A. Castro, A. Barbosa-Povoa, and E. Blanco. 2010. "A framework for evaluating firm-level supply chain performance." 17th International Annual EurOMA Conference, Porto, Portugal.

Blanco, E., Barros A., Barbosa-Povoa A. and Janakiram M., 2009. The Seven Deadly Supply Chain Phenomena. MIT CTL Working Paper.

Bechtel, C. and Jayaram, J. 1997. "Supply Chain Management: A Strategic Perspective", The International Journal of Logistics Management, Vol. 8 No. 1, pp. 15 - 34.

Cheng, R. C. H. 1994. "Selecting Input Models." In Proceedings of the 1994 Winter Simulation Conference, Edited by J. D. Tew, S. Manivannan, D. A. Sadowski, and A. F. Seila, 184-191. Piscataway, New Jersey: Institute of Electrical and Electronics Engineers, Inc.

Chien, C. 1989. "Small Sample Theory for Steady State Confidence Intervals.” Technical Report No. 37, Department of Operations Research, Stanford University, Stanford, California.

Cooper, M.C., Lambert, D.M. and Pagh, J.D. 1997. "Supply Chain Management: More Than a New Name for Logistics", The International Journal of Logistics Management, Vol. 8 No. 1, pp. 1-14.

Christopher, M. 2005. Logistics and Supply Chain Management, Prentice Hall, 3rd Edition, Harlow, England.

Gupta, S. S., K. Nagel, and S. Panchapakesan. 1973. "On the Order Statistics from Equally Correlated Normal Random Variables." Biometrika 60:403-413.

Hewitt, F. 1994. "Supply Chain Redesign." The International Journal of Logistics Management, (5) 2, 19.

Hammersley, J. M., and D. C. Handscomb. 1964. Monte Carlo Methods. London: Methuen.

Law, A. and W. Kelton. 2000. Simulation Modeling \& Analysis. 3rd ed. New York: McGraw-Hill, Inc.

Lee, H.L. and Billington, C. 1992. "Managing Supply Chain Inventory: Pitfalls and Opportunities", Sloan Management Review, Vol. 33 No. 3, pp. 65-73.

Porter, M. 1996. "What is strategy?", Harvard Business Review, Vol. 74 No. 6, pp. 61-78.

Schruben, L. 1979. "Designing Correlation Induction Strategies for Simulation Experiments." In Current Issues in Computer Simulation, edited by N. Adam and A. Dogramaci, 235-256. New York: Academic Press.

Sharon Parq Associates. 2011. WordTips: Numbering Equations. Accessed March 22. http://word.tips.net/Pages/T000273_Numbering_Equations.html.

Sheffi, Y., Rice Jr., J.B. 2005. "A supply chain view of the resilient enterprise", MIT Sloan Management Review, Vol. 47 No. 1, pp. 41-48.

Simchi-Levi, D., Kaminsky, P. and Simchi-Levi, E. 2008. Designing and Managing The Supply Chain. Concepts, Strategies and Case Studies, McGraw-Hill, 3rd Edition, Boston, USA. 
Steiger, N. M. 1999. "Improved Batching for Confidence Interval Construction in Steady-State Simulation.” Ph.D. thesis, Department of Industrial Engineering, North Carolina State University, Raleigh, North Carolina. Accessed February 7, 2011. http://www.lib.ncsu.edu/resolver/1840.16/4713.

\section{AUTHOR BIOGRAPHIES}

EDGAR E BLANCO is a Research Director at the MIT Center for Transportation \& Logistics and is the Executive Director of the MIT SCALE Network in Latin America. His current research focus is the design of environmentally efficient supply chains. He also leads research initiatives on supply chain innovations in emerging markets, disruptive mobile technologies in value chains and optimization of humanitarian operations. Prior to joining MIT, he was leading the Inventory Optimization practice at Retek (now Oracle Retail). He received his Ph.D. from the School of Industrial and Systems Engineering at the Georgia Institute of Technology. His educational background includes a B.S. and M.S. in Industrial Engineering from Universidad de los Andes (Bogotá, Colombia) and a M.S. in Operations Research from the Georgia Institute of Technology. His email address is eblanco@mit.edu.

XU YANG is a Postdoctoral Associate at the MIT Center for Transportation \& Logistics. She studies distribution network design, optimization and simulation, logistics, supply chain management, and operations management. Currently she also studies sustainable supply chains and climate change policies. She received her Ph.D. and M.S. from the Department of Industrial Engineering at the University of Louisville. Her e-mail is xu_yang@mit.edu.

ERICA GRALLA is a doctoral candidate in the Engineering Systems Division at the Massachusetts Institute of Technology. She studies supply chains for humanitarian relief and disaster response, at MIT's Center for Transportation and Logistics. In her previous work, she has studied supply chains in other challenging contexts such as emerging markets and space exploration. She holds an M.S. from MIT and a B.S.E from Princeton University. Her email address is egralla@mit.edu.

GARY GODDING is a Technologist at Intel corporation and leads the "Supply Chain Modeling \& Analytics Solutions" group. He has a Ph.D. in Computer Science from Arizona State University \& a MS in Computer Science from North Carolina State University. His e-mail address is gary.godding@intel.com.

EMILY RODRIGUEZ is currently a Supply Chain Strategy Program Manager for Intel's Materials Group. In her nearly 11 year career at Intel, she has gathered a wide breadth of supply chain experience through working in many different areas of supply/demand planning including customer, long range, factory and new product planning and has spent 3 years with Intel's Materials group working on Market Intelligence and supply chain strategy. In partnership with the various Materials operations organizations, Emily is focused on developing integrated supply chain roadmaps that turn strategy to action; from innovative designs and roadmaps to implementation. Emily holds a BS in Microbiology from San Francisco State University, an MBA from Arizona State University and is an APICS Certified Supply Chain Professional (CSCP) \& Instructor. Her e-mail address is emily.h.rodriguez@intel.com. 